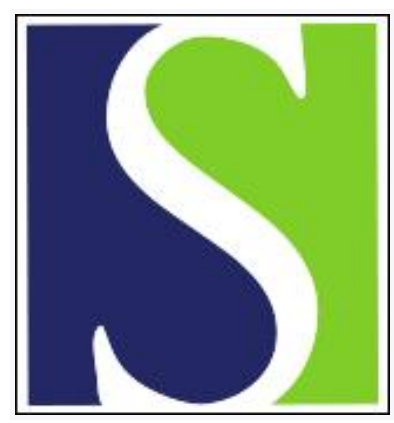

Scand J Work Environ Health 2020;46(2):117-126

https://doi.org/10.5271/sjweh.3866

Published online: 20 Nov 2019, Issue date: 01 Mar 2020

The impact of ambient temperature on the incidence of urolithiasis: a systematic review and meta-analysis

by Zhang Y, Long G, Ding B, Sun G, Ouyang W, Liu M, Ye Z, Xu H, Li H

We first confirmed there is a moderate correlation between climatic temperature and urolithiasis risk, then we ascertained the significant impact of ambient temperature on the incidence of urolithiasis. Finally, we pooled the related data and concluded that as the daily temperature increased by $5{ }^{\circ} \mathrm{C}$, the risk of urolithiasis will increase by $10 \%$ (95\% Cl: 8-11\%).

Affiliation: Department of Urology, Tongji Hospital, Tongji Medical College, Huazhong University of Science and Technology, Wuhan 430030, China. lihengtjmu@163.com

Key terms: ambient temperature; bladder stone; calculi; kidney stone; meta-analysis; nephrolithiasis; occupation; renal colic; season; systematic review; temperature; ureter stone; urolithiasis; urological disease; weather

This article in PubMed: www.ncbi.nlm.nih.gov/pubmed/31747456 


\title{
The impact of ambient temperature on the incidence of urolithiasis: a systematic review and meta-analysis
}

\author{
by Yucong Zhang, MD, 1, 2, 3* Gongwei Long, MD, 1,2* Beichen Ding, MD, 1,2 Guoliang Sun, MD, 1,2 Wei Ouyang, MD, 1,2 Man Liu, \\ $M D, 1,2$ Zhangqun Ye, PhD, ${ }^{1,2}$ Hua Xu, PhD, 1,2 Heng Li, MD ${ }^{1,2}$
}

Zhang Y, Long G, Ding B, Sun G, Ouyang W, Liu M, Ye Z, Xu H, Li H. The impact of ambient temperature on the incidence of urolithiasis: a systematic review and meta-analysis. Scand J Work Environ Health. 2020;46(2):117-126. doi:10.5271/ sjweh.3866

Objective This review aimed to confirm the association between ambient temperature and incidence of urolithiasis and evaluate the impact thereof.

Methods A systematic literature review was performed up to September 2019 using multiple databases. The effect of temperature on urolithiasis risk was assessed using risk ratio (RR). Pearson correlation coefficient (Pearson's $r$ ) was used to evaluate the linear association between ambient temperature and urolithiasis incidence. The non-linear association between climatic temperature and the urolithiasis incidence was also evaluated.

Results Twenty-four studies related to the temperature and urolithiasis risk in 14 different countries or regions of five continent involving over 2.5 million cases were included in the meta-analysis. High climatic or workplace temperature was a significant risk factor of urolithiasis. The weighted correlation coefficient (Pearson's $r$ ) of monthly temperature and urolithiasis risk was 0.49 [95\% confidence interval (CI) $0.40-0.57$ ], a moderate correlation $(0.4<r<0.6)$. According to non-linear models, as the daily temperature increases by $5{ }^{\circ} \mathrm{C}$, the risk of urolithiasis will increase by $10 \%(95 \%$ CI $8-11 \%)$.

Conclusion Both workplace and climatic temperatures are related to the incidence of urolithiasis. Public health intervention strategies need to be developed to prevent those in high-risk districts or occupations from being exposed to high ambient temperature.

Key terms bladder stone; calculi; kidney stone; nephrolithiasis; occupation; renal colic; season; ureter stone; urological disease; weather.

Urolithiasis is one of the most common urological diseases. Prevalence and incidence of urolithiasis have increased over the last decades (1). Several epidemiologic aspects have been proven to be related to the increasing likelihood of developing urinary stones, including genetics, age, sex, geography, seasonal factors, diet, and occupation (2). Many studies have indicated that there is a seasonal variation in the incidence of calculi (3-5). Temperature is especially considered to be a risk factor for urolithiasis.

Several studies suggested the linear correlation between climatic temperature and urolithiasis incidence. Geraghty et al (6) summarized these kind of studies in their systematic review (6). However, besides linear association, which was assessed using Pearson's $r$, several studies have compared the incidence of urolithiasis at different climatic temperatures to show the effect using relative risk (RR) or odds ratio (OR). Studies have also suggested that heat exposure during the work can increase the risk of urolithiasis (7-9). Therefore, we conducted this systematic review and meta-analysis to assess comprehensively the effect of ambient temperature on the incidence of urolithiasis. In addition, many studies have used non-linear regression modelling to assess the association between climatic temperature and urolithiasis incidence, and these are also summarized in this review.

1 Department of Urology, Tongji Hospital, Tongji Medical College, Huazhong University of Science and Technology, Wuhan, China.

2 Hubei Institute of Urology, Tongji Hospital, Tongji Medical College, Huazhong University of Science and Technology, Wuhan, China.

3 Department of Geriatrics, Tongji Hospital, Tongji Medical College, Huazhong University of Science and Technology, Wuhan, China.

* Yucong Zhang and Gongwei Long contributed equally to this work

Correspondence to: Heng Li, MD, Department of Urology, Tongji Hospital, Tongji Medical College, Huazhong University of Science and Technology, Wuhan 430030, China. [E-mail: lihengtjmu@163.com]. 


\section{Methods}

\section{Literature search}

We conducted a comprehensive literature search for studies published before 10 September 2019 in PubMed, Web of Science and Scopus according to the Preferred Reporting Items for Systematic Review and Meta-Analysis (PRISMA) statement using the search strategy: (climate OR weather OR season OR occupation OR work) AND (urolithiasis OR calculi OR nephrolithiasis OR renal colic OR kidney stone OR ureter stone OR bladder stone) AND (temperature OR heat OR hot). The exact search string is available in the supplementary material (www.sjweh. fi/show_abstract.php?abstract_id=3866, Document 1). The titles and abstracts of articles that were identified by the keyword search were screened against the study selection criteria. Potentially relevant articles were independently retrieved or evaluated for the full text. We also conducted a reference list and cited reference search from full-text articles that met the study criteria. Two independent reviewers screened all studies according to inclusion and exclusion criteria, and all disagreements were solved by discussion with a third author.

\section{Study selection criteria}

Studies that met the following criteria were included in this systematic review: (i) Participants: no specific requirements for participants, but the control group should be from the same population of the exposure group. (ii) Exposures: high climatic temperatures (with actual number above average local climatic temperature) or workplace with heat exposure. (iii) Comparator: normal or low climatic temperatures (with actual number not exceeding average local climatic temperature) or workplace without heat exposure. (iv) Outcomes: the events of urolithiasis, renal colic, or stone treatments were used as proxy of urolithiasis incidence. Outcomes contained at least one set of the following statistics: (a) duration of the study and Pearson correlation coefficient (Pearson's $r$ ) of mean monthly temperature and incidence of urolithiasis; (b) RR with $95 \%$ confidence intervals (CI) of two different climatic temperatures or RR with $95 \%$ CI of comparison of workplace with or without heat exposure or they could be calculated from related data; (c) increased RR ratio (IRR) with $95 \%(\mathrm{CI})$ as mean daily temperature increased by a clear value. (v) Language: articles were written in English.

\section{Data extraction and quality assessment}

Two reviewers independently extracted data from every included study using a standardized form according to the PRISMA statement and evaluated all relevant clinical studies for methodological quality. The following information was extracted from each study: the name of the first author; year of publication; study location; study period; number of cases; Pearson's $r$; RR for different ambient temperature; relative RR as mean daily temperature increased by a clear value (IRR). For convenience, the term RR (relative risk) will be used as a generic term for relative odds (cumulative incidence data), rate ratio (incidence-rate data) and OR (case-control data). Due to the lack of scales targeting time-series analysis study or case-crossover study, we created a scale - which combined several items from the New Castle-Ottawa Scale (www.ohri.ca/programs/clinical_epidemiology/ oxford.asp) and the Cochrane risk of bias tool (10) - to assess the quality of these kinds of studies (supplementary Document 2). The quality of case-control study was evaluated using the New Castle-Ottawa Scale and the quality of cross-sectional study was evaluated using the Joanna Briggs Institution Checklist for Analytical Cross Sectional Study (joannabriggs.org/research/criticalappraisal-tools.html).

\section{Data analysis}

Pooled estimates of the Pearson's $r$ were calculated by transforming each $r$ into Fisher's $\mathrm{Z}$ value. The resulting value was then weighted with the inverse of the variance of the correlation coefficients. The $95 \%$ CI of the pooled weighted Fisher's Z coefficients was also calculated, after which all of the values were back-transformed into $r$ using the following formula (11):

$$
\begin{gathered}
\text { Fisher's } \mathrm{Z}=0.5 \times \ln \frac{1+r}{1-r} \\
v_{z}=\frac{1}{n-3} \\
S_{E}=\sqrt{v_{z}} \\
\text { Summary } r=\frac{e^{2 z}-1}{e^{2 z}+1}
\end{gathered}
$$

To assess the non-linear association between increasing temperature and the incidence of urolithiasis, all IRR were standardized to an increase of $5^{\circ} \mathrm{C}$ in climatic temperature. For studies reporting $\operatorname{IRR}_{\mathrm{u}}$ per $\mathrm{U}^{\circ} \mathrm{C}$ instead of standard level (eg, ten units), the $\mathrm{IRR}_{\text {standardised }}$ was calculated by the formula:

$$
\mathrm{IRR}_{\text {standardized }}=\operatorname{IRR}_{u} \frac{5}{u}
$$

where $\mathrm{U}$ is the increment used in the original study to estimate the effects. 
Potential publication bias was evaluated by using Egger's linear regression test (with significance defined as $\mathrm{P}<0.05$ ). Heterogeneity between studies was tested using both the $I^{2}$ tests $\left(I^{2}<30 \%\right.$ defined mild heterogeneity; $30 \% \leq I^{2} \leq 50 \%$, moderate heterogeneity; and $I^{2}>50 \%$, high heterogeneity). When heterogeneity was detected, the random effects model was adopted. If not, the fixed effects model was adopted (12). When results from fixed and random effects models were different from moderate heterogeneity (ie, $I^{2}=30-50 \%$ ), we presented the latter as it represents a more conservative approach (13).

The pooled estimates of Fisher's Z and IRR were conducted using RevMan 5.3 (the Nordic Cochrane Centre, Copenhagen, Denmark). The calculating of Egger's linear regression test was conducted in STATA version 12.0 (Stata Corp, College Station, TX, USA). A subgroup analysis was planned beforehand to assess the effects of high climatic temperature and occupational heat exposure respectively. No sensitivity analysis was conducted.

Considering the heterogeneity of studies that evaluated the effect of climatic and workplace temperature using RR, a meta-analysis was not conducted. However, forest plots were still provided in order to present a visual representation of the direction and magnitude of these results.

\section{Results}

\section{Characteristics of included studies}

After removing duplicates, the initial database search yielded a total of 684 articles. After screening these titles and abstracts, 69 articles remained for full-text evaluation. Only 24 articles were eligible under the full-text assessment (figure 1). Of these, 9 studies directly investigated the impact of ambient temperature on urolithiasis using RR (7-9, 14-19), 12 time-series studies evaluated the linear correlation between mean monthly temperature and incidence of urolithiasis $(5,20-30)$, and 6 time-series studies estimated the increased $\mathrm{RR}$ as mean daily temperature increased to evaluate the non-linear association (28-33).

Tables 1-3 summarize the 24 studies that investigated the association between temperature and urolithiasis. Of these, 19 were time-series analyses, 4 were cross-sectional studies, and 1 was a case-control study. In terms of origin, 10 were from Asia, 5 from Europe, 6 from North America, 2 from Australia, and 1 was from South America. Emergency room (ER) visits were used in 15 studies to estimate the incidence of urolithiasis. Among these articles, 11 used ER presentation for renal colic, 4 demonstrated ER data for proven stones. Besides

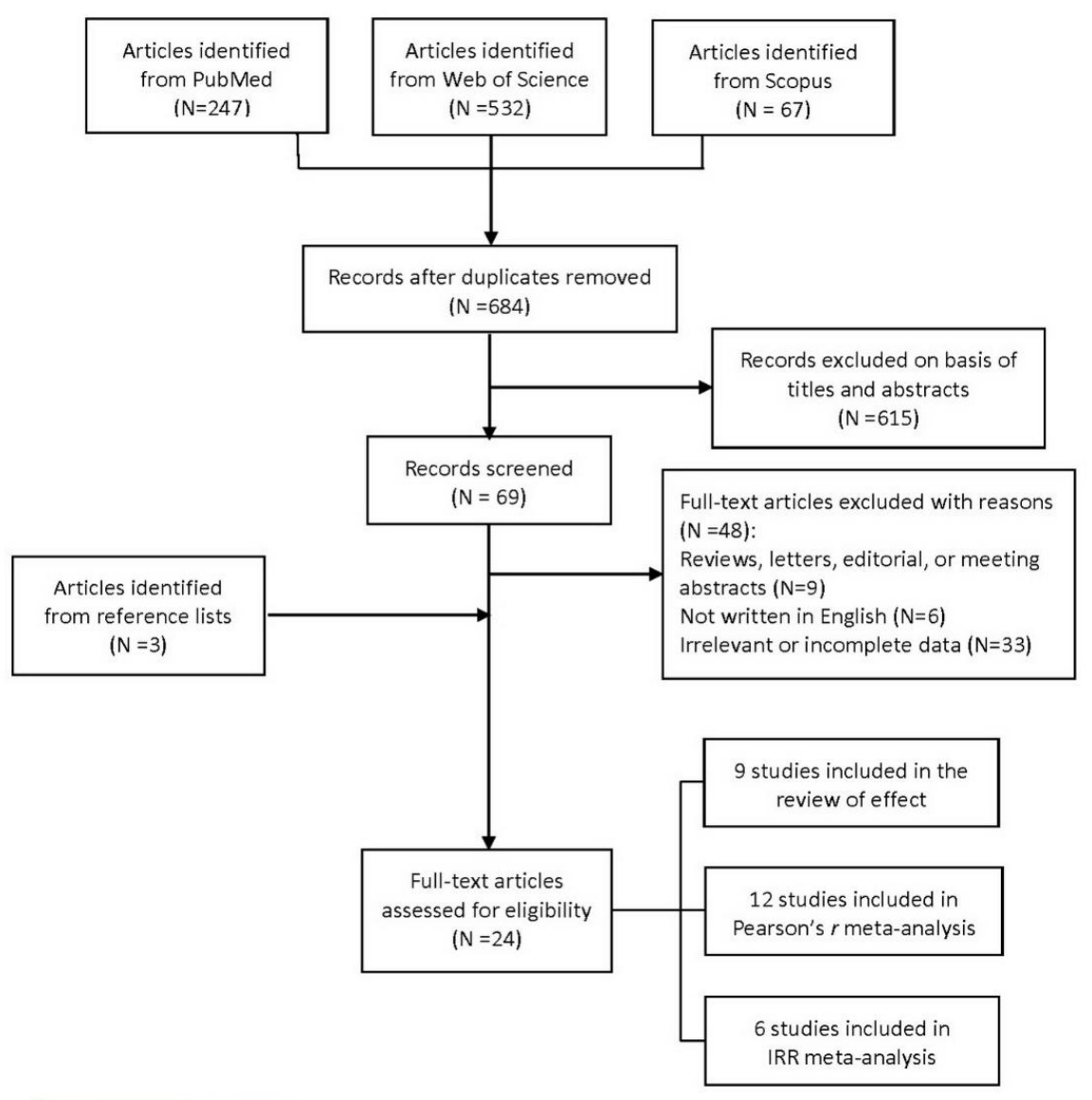

Figure 1. Flow chart of the study searching, screening and including. 
Table 1. Characteristics of studies that assessed the effect of ambient temperature. [CS=cross-sectional study; CC=case-control study; TS =timeseries study; RR=relative risk].

\begin{tabular}{|c|c|c|c|c|c|c|c|c|}
\hline Study & Country & Study period & Risk parameters & $\begin{array}{l}\text { Cases } \\
\text { (N) }\end{array}$ & $\begin{array}{l}\text { Study } \\
\text { type }\end{array}$ & $\mathrm{RR}(95 \% \mathrm{Cl})$ & Exposure and dose & Confounders \\
\hline $\begin{array}{l}\text { Lee et al, } \\
2016(14)\end{array}$ & Korea & $2005-2013$ & $\begin{array}{l}\text { Patients visiting emer- } \\
\text { gency department as } \\
\text { proven stones }\end{array}$ & 14518 & TS & $2.54(1.67-3.87)^{\mathrm{a}}$ & $\begin{array}{l}\text { Daily mean temperature } \\
29^{\circ} \mathrm{C} \text { versus } 13^{\circ} \mathrm{C}\end{array}$ & $\begin{array}{l}\text { Humidity, sea level, } \\
\text { pressure, sunshine }\end{array}$ \\
\hline $\begin{array}{l}\text { Ordon et al, } \\
2016(15)\end{array}$ & Canada & 2002-2013 & $\begin{array}{l}\text { Patients visiting emer- } \\
\text { gency department for } \\
\text { renal colic }\end{array}$ & 423396 & TS & $1.30(1.20-1.42)^{a}$ & $\begin{array}{l}\text { Daily mean temperature } \\
21.1^{\circ} \mathrm{C} \text { versus }-7.0^{\circ} \mathrm{C}\end{array}$ & $\begin{array}{l}\text { Age, sex, income, residence } \\
\text { region, basic diseases }\end{array}$ \\
\hline $\begin{array}{l}\text { Safarinejad } \\
\text { et al, } 2007 \\
\text { (17) }\end{array}$ & Iran & 2005 & $\begin{array}{l}\text { Prevalence obtained } \\
\text { from } 30 \text { counties of Iran } \\
\text { using questionnaire }\end{array}$ & 436 & CS & $1.9(1.7-2.2)^{a}$ & $\begin{array}{l}\text { Mean annual temperature } \\
>26^{\circ} \mathrm{C} \text { versus }<15^{\circ} \mathrm{C}\end{array}$ & $\begin{array}{l}\text { Obesity, hypertension, } \\
\text { unemployment, consump- } \\
\text { tion of liquid, cola, meat } \\
\text { and coffee }\end{array}$ \\
\hline $\begin{array}{l}\text { Tasian et al, } \\
2014 \text { (18) }\end{array}$ & USA & $2005-2011$ & $\begin{array}{l}\text { Patients who sought } \\
\text { medical evaluation or } \\
\text { treatment of kidney } \\
\text { stones in } 5 \text { cities }\end{array}$ & 60433 & TS & $\begin{array}{l}1.38(1.07-1.79)^{\text {a }} \\
1.37(1.07-1.76)^{\text {a }} \\
1.36(1.10-1.69)^{\text {a }} \\
1.11(0.73,1.68)^{\text {a }} \\
1.47(1.00-2.17)^{\text {a }}\end{array}$ & $\begin{array}{l}\text { Daily temperature } 30^{\circ} \mathrm{C} \\
\text { versus } 10^{\circ} \mathrm{C} \text { in Atlanta } \\
\text { Daily temperature } 30^{\circ} \mathrm{C} \\
\text { versus } 10^{\circ} \mathrm{C} \text { in Chicago } \\
\text { Daily temperature } 30^{\circ} \mathrm{C} \\
\text { versus } 10^{\circ} \mathrm{C} \text { in Dallas } \\
\text { Daily temperature } 30^{\circ} \mathrm{C} \\
\text { versus } 10^{\circ} \mathrm{C} \text { in Los Angeles } \\
\text { Daily temperature } 30^{\circ} \mathrm{C} \\
\text { versus } 10^{\circ} \mathrm{C} \text { in Philadelphia }\end{array}$ & Relative humidity \\
\hline $\begin{array}{l}\text { Yang et al, } \\
2016(19)\end{array}$ & China & 2008-2012 & $\begin{array}{l}\text { Daily ambulance dis- } \\
\text { patches for renal colic } \\
\text { from emergency center }\end{array}$ & 3158 & TS & $1.92(1.21-3.05)^{\text {a }}$ & $\begin{array}{l}\text { Daily temperature } 30.7^{\circ} \mathrm{C} \\
\text { versus } 21^{\circ} \mathrm{C}\end{array}$ & Humidity \\
\hline $\begin{array}{l}\text { Atan et al, } \\
2005(7)\end{array}$ & Brazil & 1999-2002 & $\begin{array}{l}\text { Prevalence in male work- } \\
\text { ers at a large steel plant }\end{array}$ & -181 & CS & $9.98(7.39-13.47)^{\mathrm{b}}$ & $\begin{array}{l}\text { Hot work area }\left(>45^{\circ} \mathrm{C}\right) \\
\text { versus non-hot work area } \\
\text { (room temperature) }\end{array}$ & \\
\hline $\begin{array}{l}\text { Borghi et } \\
\text { al, } 1993(8)\end{array}$ & Italy & unclear & $\begin{array}{l}\text { Prevalence in male } \\
\text { machinists at a large } \\
\text { glass plant }\end{array}$ & 24 & CS & $3.73(1.25-11.12)^{b}$ & $\begin{array}{l}\text { Hot work area }\left(29-31^{\circ} \mathrm{C}\right) \text { versus } \\
\text { non-hot work area }\left(24-27^{\circ} \mathrm{C}\right)\end{array}$ & \\
\hline $\begin{array}{l}\text { Luo et al, } \\
2014(9)\end{array}$ & China & $2003-2010$ & $\begin{array}{l}\text { Prevalence in workers at } \\
\text { a shipbuilding company }\end{array}$ & 190 & $\mathrm{CC}$ & $\begin{array}{l}6.1(3.4-10.9)^{b} \\
3.6(2.0-6.6)^{b} \\
3.5(1.9-6.3)^{b} \\
6.4(2.9-13.9)^{b} \\
7.2(1.9-27.4) \\
6.9(2.7-17.7)^{b} \\
4.3(1.3-14.6)^{b}\end{array}$ & $\begin{array}{l}\text { Welder versus Indoor } \\
\text { Assembler versus Indoor } \\
\text { PSQI (Production security and } \\
\text { quality inspector) versus indoor } \\
\text { Smelter worker versus indoor } \\
\text { Planing machine operator } \\
\text { versus indoor } \\
\text { Spray painter versus indoor } \\
\text { Gas-cutting worker versus } \\
\text { indoor }\end{array}$ & \\
\hline $\begin{array}{l}\text { Pin et } \\
\text { al, } 1992 \\
(16)\end{array}$ & Singapore & unclear & $\begin{array}{l}\text { Prevalence in male } \\
\text { workers in several } \\
\text { occupations }\end{array}$ & 16 & $\mathrm{CS}$ & $5.53(0.72-42.77)^{b}$ & Outdoor versus indoor & \\
\hline
\end{tabular}

a The presented RR of climatic temperature were adjusted for confounders.

${ }^{\mathrm{b}}$ The presented RR of workplace heat exposure were crude data without adjustment for confounders.

ER presentation, number of patients who sought medical evaluation and records of hospitalizations for proven stones were used respectively in 2 studies. The prevalence of calculi was used in 5 studies as a proxy for risk of urolithiasis. The records of extracorporeal shockwave lithotripsy (ESWL), emergency ambulance dispatches, and the number of stones submitted to the biochemistry department to evaluate the stone formation were each used in 1 study, respectively.

In the quality assessment of time-series analyses, 7 studies were considered to be of good quality, 11 intermediate quality, and 1 of low quality (supplementary table S2). Supplementary table S3 summarizes the quality of cross-sectional studies with one considered to be of low quality. The case-control study was considered to be good quality using the Newcastle-Ottawa Scale (supplemental table S4).

\section{Effect of ambient temperature on urolithiasis risk assessed with relative risk}

RR information was complete in 9 studies and these were included in the systematic review. The overall effects of ambient temperature on urolithiasis risk were not calculated due to the heterogeneity of exposure measurement. The effect of climatic temperature (figure 2A) was assessed in 5 studies: 4 compared the daily urolithiasis events of different temperature $(14,15,18$, 19). Most studies reported significantly different urolithiasis risks, with two temperatures differing as much as $10^{\circ} \mathrm{C}$ in Yang et al's study (19) to $28^{\circ} \mathrm{C}$ in Ordon et al's study (15). However, Tasian et al reported data from five US metropolitan areas, and the RR of urolithiasis cases in Los Angeles did not reach statistical between temperatuers of $10-30{ }^{\circ} \mathrm{C}(18)$. In fact, the RR stopped 
Table 2. Characteristics of studies that assessed linear correlation using Pearson's $r$ of monthly climatic temperature and incidence of urolithiasis. $[R C=$ =emergency room (ER) visits for renal colic; $S S=$ stones submitted to the biochemistry department; $E S W L=$ records of extracorporeal shockwave lithotripsy; PS=ER visits for proven stones; NS=Not specified].

\begin{tabular}{|c|c|c|c|c|c|c|c|}
\hline Study & $\begin{array}{l}\text { Study period and } \\
\text { number of months }\end{array}$ & Country & $\begin{array}{l}\text { Case } \\
\text { type }\end{array}$ & Data source & Cases (N) & $\begin{array}{c}\text { Pearson's } \\
r\end{array}$ & Confounders \\
\hline al-Hadramy et al, 1997 (5) & $1992-1994(N=36)$ & Saudi Arabia & $\mathrm{RC}$ & 1 hospital & $1342^{\mathrm{a}}$ & 0.67 & Air pressure, humidity \\
\hline Buttigieg et al, 2016 (20) & $2009-2011(\mathrm{~N}=36)$ & Malta & SS & 1 hospital & 389 & 0.49 & Humidex, humidity \\
\hline Cepeda et al, 2015 (21) & $2005-2013(\mathrm{~N}=108)$ & Spain & $\mathrm{RC}$ & 1 hospital & 9330 & 0.336 & Humidity, sunshine \\
\hline Chauhan et al, 2004 (22) & $1996-2002(N=84)$ & USA & $\mathrm{RC}$ & 15 New Jersey ER & 30358 & 0.42 & NS \\
\hline Chen et al, 2008 (23) & $1999-2003(\mathrm{~N}=60)$ & Taiwan & $\mathrm{RC}$ & All patients in Taiwan & 270302 & 0.517 & Air pressure, sunshine \\
\hline Condemi et al, 2015 (28) & $2007-2010(\mathrm{~N}=48)$ & Italy & $\mathrm{RC}$ & 1 hospital & 4051 & 0.60 & Age, air pressure \\
\hline Gaziev et al, 2016 (24) & $2007-2009(N=35)$ & Italy & $\mathrm{RC}$ & 1 hospital & 2682 & 0.611 & Air pressure, humidity \\
\hline Lin et al, 2014 (25) & $2006-2011(N=60)$ & Taiwan & ESWL & 1 hospital & 6616 & 0.696 & $\begin{array}{l}\text { Humidity, rainfall, air } \\
\text { pressure, sun, wind }\end{array}$ \\
\hline Lo et al, 2010 (29) & 1999-2007 (N=108) & New Zealand & $\mathrm{RC}$ & $\begin{array}{l}\text { All public hospitals } \\
\text { in Auckland }\end{array}$ & 7668 & 0.40 & Sunshine \\
\hline Park et al, 2015 (30) & $2006-2010(N=60)$ & Korea & $\mathrm{RC}$ & Nationwide data & 1702913 & 0.557 & $\begin{array}{l}\text { Humidity, sunshine, air } \\
\text { pressure }\end{array}$ \\
\hline Sirohi et al, 2014 (26) & $2007-2012(N=72)$ & USA & PS & 1 hospital & 3647 & 0.3995 & Humidity, rainfall, air pressure \\
\hline Freeg et al, 2012 (27) & $2007-2009(\mathrm{~N}=36)$ & UAE & PS & 1 hospital & 458 & 0.079 & Humidity \\
\hline
\end{tabular}

a The data was calculated from the given monthly case number.

Table 3. Characteristics of studies that evaluated non-linear association using increased relative risk (IRR). [ER=emergency room.]

\begin{tabular}{|c|c|c|c|c|c|c|}
\hline Source author & Study period & Country & Case type & Data source & Cases (N) & IRR and $95 \% \mathrm{Cl}$ \\
\hline Borg et al, 2017 (31) & $2003-2014$ & Australia & ER admissions for renal colic & $\begin{array}{l}\text { All metropolitan hospitals } \\
\text { in Adelaide }\end{array}$ & 19171 & $\begin{array}{r}1.016(1.011-1.020) / \\
1{ }^{\circ} \mathrm{C}\end{array}$ \\
\hline $\begin{array}{l}\text { Condemi et al, } 2015 \\
\text { (28) }\end{array}$ & $2007-2010$ & Italy & ER visits for renal colic & $\begin{array}{l}\text { S. Croce and Carle } \\
\text { Hospital of Cuneo }\end{array}$ & 4051 & $\begin{array}{r}1.11(1.03-1.19) / \\
5^{\circ} \mathrm{C}\end{array}$ \\
\hline \multirow[t]{2}{*}{ Fletcher et al, 2012 (32) } & $1991-2004$ & USA & $\begin{array}{l}\text { Acute-care hospital admissions } \\
\text { as renal calculi }\end{array}$ & New York State & 34087 & $\begin{array}{r}1.06(1.05-1.08) / \\
5^{\circ} \mathrm{C}\left(2.78^{\circ} \mathrm{C}\right)\end{array}$ \\
\hline & & & $\begin{array}{l}\text { Acute-care hospital admissions } \\
\text { as lower urinary calculi }\end{array}$ & New York State & 2205 & $\begin{array}{r}1.09(1.04-1.16) / \\
5^{\circ} \mathrm{C}\left(2.78^{\circ} \mathrm{C}\right)\end{array}$ \\
\hline Lo et al, 2010 (29) & 1999-2007 & New Zealand & ER visits for renal colic & $\begin{array}{l}\text { All public hospitals in } \\
\text { Auckland }\end{array}$ & 7668 & $\begin{array}{r}1.028(1.013-1.043) / \\
1{ }^{\circ} \mathrm{C}\end{array}$ \\
\hline Park et al, 2015 (30) & $2006-2010$ & Korea & ER visits for renal colic & Nationwide data & 1702913 & $\begin{array}{r}1.0171(1.0102-1.0241) / \\
10^{\circ} \mathrm{C}\end{array}$ \\
\hline Malig et al, 2019 (33) & 1999-2009 & USA & $\begin{array}{l}\text { Records of hospitalizations } \\
\text { due to kidney stone }\end{array}$ & $\begin{array}{l}\text { Statewide data of } \\
\text { California }\end{array}$ & NS & $\begin{array}{r}1.152(1.103-1.204) ! \\
10^{\circ} \mathrm{C}\left(5.56^{\circ} \mathrm{C}\right)\end{array}$ \\
\hline
\end{tabular}

rising after $15{ }^{\circ} \mathrm{C}$, and considering the relatively lower urolithiasis incidence compared to other cities (167 kidney stone incidence per 100000 in Los Angeles and 256 per 100000 in Philadelphia, which is the lowest of the other four cities), the Mediterranean climate of Los Angeles and other socioeconomic factors might be the reason for the insignificance of the RR. In their analysis of the average annual temperatures reported, Safarinejad et al (17) concluded that higher annual temperature levels were related to more urolithiasis events.

The effect of occupational heat exposure was investigated in 4 studies (figure 2B). Pin et al (16) compared the prevalence of stone diseases of five occupations and found that urolithiasis occurred more among outdoor workers (15 of 288) than indoor workers (1 of 118), though this was not statistically significant (16). Borghi et al (8) then compared the calculi prevalence of workers exposed to hot temperatures (Wet Bulb Globe Temperature, WBGT: 29-31 ${ }^{\circ} \mathrm{C}$ ) against those of workers in normal temperature (WBGT: $24-27^{\circ} \mathrm{C}$ ) at a glass plant in Italy, and significant differences were found (20 of 236 in hot temperature versus 4 of 165 in normal temperature). Another study conducted at a steel industry in Brazil by Atan et al (7) also supported the effect of heat exposure, in which the hot-area workers (103 of 1289) had a significantly higher prevalence of urolithiasis than those who worked in areas at room temperature (78 of 9037). In their research that focused on workers in a shipbuilding company in China, Luo at al (9) also reported relatively higher urolithiasis risk among the outdoor workers.

It should be noted that the studies that assessed the effect of temperature using RR were quite heterogeneous in study design, and the quality assessment of these studies were based on three different instruments. Therefore, these conclusions should be interpreted with caution.

\section{Linear association of climatic temperature and urolithiasis risk}

To pool the linear association between monthly temperature and urolithiasis risk, 11 studies containing Pearson's $r$ were included. The Fisher's Z was 0.53 $(95 \%$ CI $0.41-0.65)$ and the summary $r$ was $0.49(95 \%$ CI 0.40-0.57) (figure 3 ), which means a moderate association $(0.4<r<0.6)$. 
Study

ID

\begin{tabular}{|c|c|c|}
\hline A.Climatic temperature & & \\
\hline Lee, S.2016 & $\longrightarrow$ & $2.54(1.67,3.87)$ \\
\hline Ordon, M.2016 & $\bullet$ & $1.30(1.19,1.42)$ \\
\hline Safarinejad, M. R.2007 & $\rightarrow$ & $1.90(1.70,2.12)$ \\
\hline Tasian, G. E.2014 Atlanta & $\rightarrow$ & $1.38(1.06,1.79)$ \\
\hline Tasian, G. E.2014 Chicago & $\rightarrow$ & $1.37(1.07,1.76)$ \\
\hline Tasian, G. E.2014 Dallas & $\rightarrow$ & $1.36(1.09,1.69)$ \\
\hline Tasian, G. E.2014 Los Angeles & + & $1.11(0.73,1.68)$ \\
\hline Tasian, G. E.2014 Philadelphia & $\rightarrow$ & $1.47(0.99,2.17)$ \\
\hline Yang, C.2016 & $\longrightarrow$ & $1.92(1.21,3.05)$ \\
\hline B.Occupational heat exposure & & \\
\hline Atan, L.2005 & $\rightarrow$ & $9.97(7.39,13.46)$ \\
\hline Borghi, L.1993 & & $3.74(1.26,11.15)$ \\
\hline Luo, H.2014 Assembler & - & $3.60(1.96,6.59)$ \\
\hline Luo, H.2014 Gas-cutting worker & & $4.31(1.27,14.63)$ \\
\hline Luo, H.2014 PMO & & $7.17(1.88,27.29)$ \\
\hline Luo, H.2014 PSQI & & $3.49(1.94,6.28)$ \\
\hline Luo, H.2014 Smelter worker & & $6.42(2.96,13.96)$ \\
\hline Luo, H.2014 Spray painter & & $6.89(2.68,17.69)$ \\
\hline Luo, H.2014 Welder & 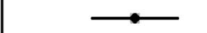 & $6.11(3.42,10.92)$ \\
\hline Pin, N. T.1992 & & $5.53(0.71,42.79)$ \\
\hline 1 & & \\
\hline .0234 & 1 & \\
\hline
\end{tabular}

Figure 2. The forest plot of the effect of ambient temperature on incidence of urolithiasis. The overall effects were not calculated because of the heterogeneity of exposure measurement, and forest plots were provided for visual representation of outcomes. [SE=standard error; $\mathrm{Cl}=$ confidence interval]. (A) The effect of climatic temperature on urolithiasis incidence; $(B)$ the effect of heat exposure during work on urolithiasis incidence.

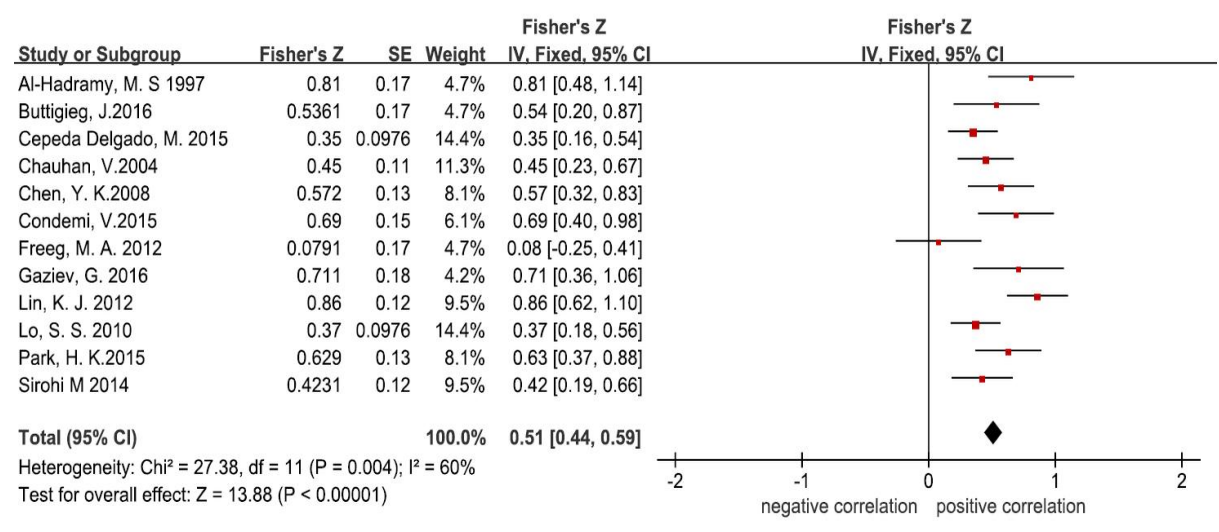

Figure 3. The forest plot of the Pearson's $r$ of monthly mean temperature and incidence of urolithiasis. [SE=standard error; $\mathrm{Cl}=$ confidence interval].
Related statistics of three regions were reported in 2 studies. After pooling the related outcomes, we found that in the USA, the association was weak to moderate $(r=0.41,95 \%$ CI $0.27-0.54)$, while in Italy and Taiwan, the association was moderate to strong $(r=0.60,95 \%$ CI $0.44-0.73 ; r=0.62,95 \%$ CI $0.41-0.76)$. Then we performed a subgroup analysis based on the countries. In Europe (Malta, Spain, and Italy), the association was weak to moderate $(r=0.49,95 \%$ CI $0.34-0.62)$, and in East Asia (Taiwan and Korea) a moderate-to-strong association was suggested ( $r=0.60,95 \%$ CI $0.48-0.70)$. Notably, though Saudi Arabia and United Arab Emirates are neighboring countries, the reported association between temperature and incidence of urolithiasis was vastly different, and the economic conditions and lifestyles might be the sources of difference.

\section{The non-linear association of climatic temperature and urolithiasis risk}

In addition to studies that assessed the linear association between climatic temperature and urolithiasis risk, many were assessed non-linear associations, 6 of which were included in our analysis (figure 4) (28-33). All these studies consistently reported that the urolithiasis risk increased with the daily temperature. Our findings show that when the daily increased by $5{ }^{\circ} \mathrm{C}$, the urolithiasis risk increased by $10 \%(95 \%$ CI $8-11 \%)$.

\section{Publication biases}

The publication bias of the analysis of Pearson's $r$ using Egger's test was not significant $(\mathrm{P}=0.279)$. The funnel 


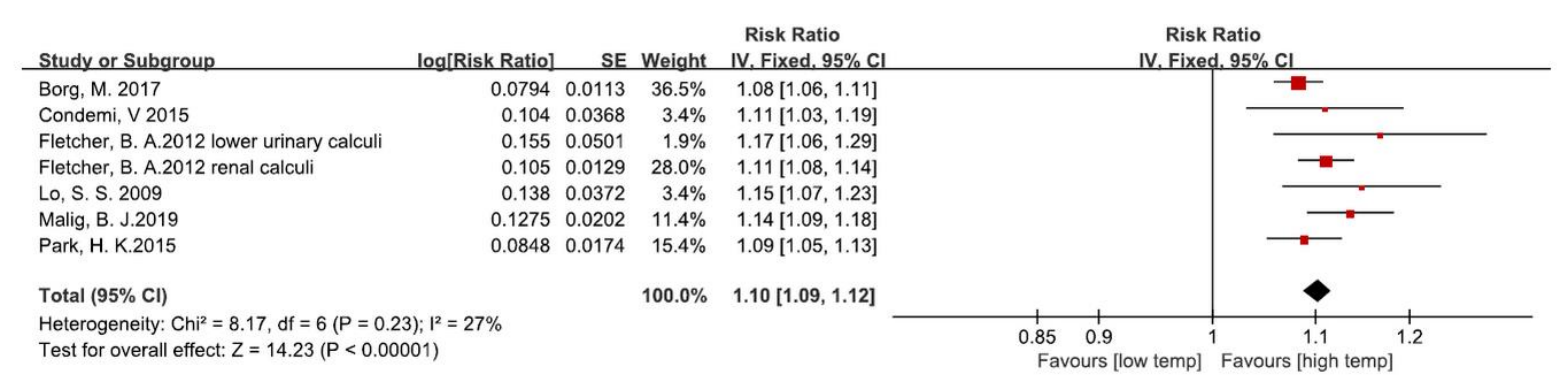

Figure 4. The forest plot of the non-linear association between daily mean temperature and incidence of urolithiasis. The risk ratio was the standardized increased risk ratio for per 5 Celsius degree increment. [SE=standard error; $\mathrm{Cl}=$ confidence interval].

plot is shown in figure 5A, and two studies suggested biases. After excluding the biased studies, the outcomes remained consistent with the previous results (Fisher's Z: $0.50 ; 95 \%$ CI $0.42-0.58$ ). The results of the nonlinear association analysis showed no publication bias (Egger's test: $\mathrm{P}=0.095$; figure 5B).

\section{A. Funnel plot of linear association analysis}

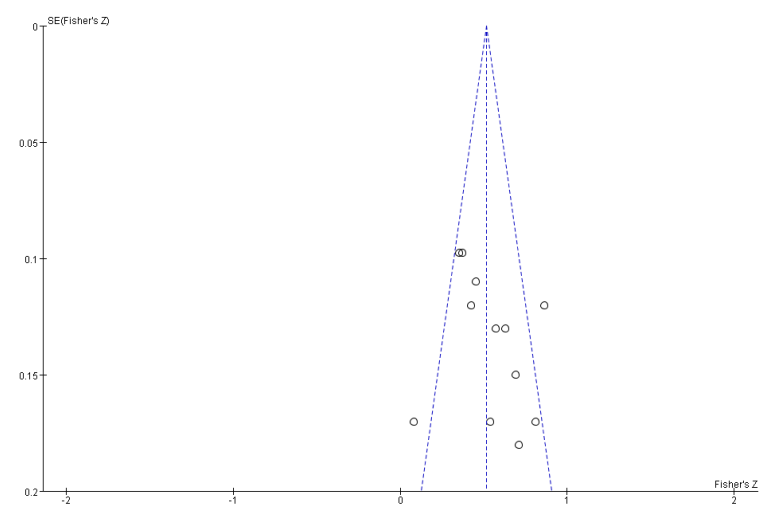

B. Funnel plot of non-linear association analysis

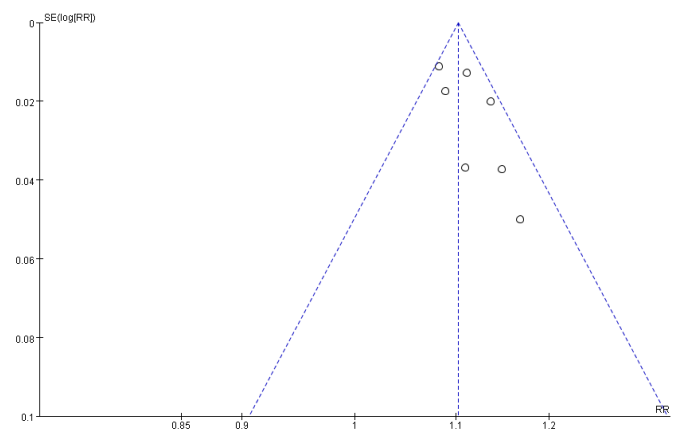

Figure 5. (A) The funnel plot of the linear association between monthly mean temperature and incidence of urolithiasis. (B) The funnel plot of the non-linear association between daily mean temperature and incidence of urolithiasis. The risk ratios was standardized to increased risk ratio for per $5^{\circ} \mathrm{C}$ increment. [SE=standard error; $\mathrm{Cl}=$ confidence interval.]

\section{Discussion}

The present systematic review and meta-analysis analyzed 24 studies and demonstrated a significant positive association between ambient temperature and risk of urolithiasis. Our study suggested that the increased temperature in climate and workplace could significantly increase urolithiasis incidence.

To assess the linear association between climatic temperature and urolithiasis risk, Pearson's $r$ of mean monthly temperature was extracted. However, in addition to mean monthly temperature, other temperature parameters may be related to the incidence of urolithiasis. Both Cepeda Delgado's and Lin's studies revealed that the monthly maximum, average, and minimum temperature were all linearly related to the risk of urolithiasis $(21,25,34)$. Daily data were also used in several studies, and Cervellin et al found a significant association between the mean number of cases of renal colic per day and the mean daily temperature (positive association, $\mathrm{r}=0.93 ; \mathrm{P}<0.0001)(35,36)$. In another study, the daily maximum, average, and minimum temperature were all significantly related to the incidence of urolithiasis (37). Furthermore, two articles suggested an association between annual mean temperature and urolithiasis $(17,38)$. It has been proposed that global warming will lead to an increase of 1.6-2.2 million lifetime cases of urolithiasis by 2050 in US, which might be as high as $30 \%$ in some areas (39). These articles support our conclusion and the need for greater action on global warming to decrease the risk of urolithiasis. However, more research is needed as there are still some studies that do not support the relationship between temperature and urolithiasis $(27,40)$. We excluded Power's study (40) from the meta-analysis, but the mild climatic of Britain could be a reason for the insignificant result.

Regarding the studies that compared different temperature using RR, we did not conduct a meta-analysis to calculate the overall effect due to heterogeneity as these studies comprised different designs, and both prevalence 
and incidence were used. The dose of exposure was also a source of heterogeneity. For studies investigating climatic temperature, the normal climatic temperature of different districts was diverse, and the temperature used for comparison also varied in these studies. For studies focusing on workplace temperature, the measurement of temperature was hard and the heat exposure of different types of work also differed.

There was a difference between the effect of climatic and workplace temperatures on the incidence of urolithiasis (figure 2). One probable reason is that the heat exposure in work can reach as much as $50{ }^{\circ} \mathrm{C}$, which is much higher than normal climatic temperature (7). Moreover, when the climatic temperature increases, people tend to stay indoors with air conditioning, which may reduce the effect. Another explanation is that heat exposure at work is consistent for years, and the heavy physical burden could have aggravated the effect. Apart from these reasons, the quality and quantity of studies included may have an effect on these outcomes. The data collected for heat exposure at work were crude (ie, without adjustment for confounders) and may have resulted in an overestimation of the effect. For example, in the study that compared several outdoor occupations, the OR of planning machine operator (unadjusted: $\mathrm{P}<0.01$; adjusted: $\mathrm{P}=0.06$ ) and gas-cutting worker (unadjusted: $\mathrm{P}=0.02$; adjusted: $\mathrm{P}=0.15$ ) were insignificant after adjustment for exposure time and blood pressure. But adjusted OR of other occupations and the overall difference between outdoor and indoor workers remained significant.

We had a theory on the mechanisms behind the relation of temperature and incidence of urolithiasis. Heat exposure can result in sweating, leading to decreased extracellular fluid (ECF) and subsequent dehydration (41). Low ECF leads to increased secretion of vasopressin, which promotes reabsorption of water from the renal filtrate and increases urinary concentration $(42,43)$. The increased urinary calcium and super-saturation of calcium oxalate and calcium phosphate may significantly increase the risk of calculi. The relatively lower RR in Ordon's study may support this theory because the climatic temperature of this Canadian study is obviously lower than in other studies and, therefore, the dehydration might not significantly increase at $21^{\circ} \mathrm{C}(15)$. The insignificant outcome of the study conducted in Britain may also support this (40).

To our knowledge, the present study is the first meta-analysis to estimate the effect of temperature on the incidence of urolithiasis. This review is based on worldwide data from 14 different countries involving over 2.5 million cases. We evaluated the linear correlation between temperature and urolithiasis by pooling Pearson's $r$ using data over 707 months. We further estimated the non-linear correlation that the risk of uro- lithiasis increased by $10 \%$ (95\% CI 8-11\%) with each $5{ }^{\circ} \mathrm{C}$ increment in temperature.

This study had some limitations, including low evidence level of included studies, potential improper assessment of study quality, and potential misclassification of heat exposure. Most of the included studies were time-series analyses, which do not strongly indicate causal relationships. We adopted the standard to assess the quality of time-series analysis from authoritative scales, but it has not been well tested. Therefore, we tried not to overestimate quality. We were unable to measure heat exposure accurately in these studies because the coverage of each study is vast and the climatic temperature varies inside the district. Hence, we added the matching degree of climate and district to the quality assessment. In addition, because of the resource restraints, we only included English articles, but several studies in Russia, Spanish and other languages might have contained relevant outcomes. Lastly, confounders such as drinking habits and physical burden were not well controlled for in original outcomes, and we are unlikely to have eliminated all biases.

\section{Concluding remarks}

In summary, there is an association between temperature and incidence of urolithiasis. The high temperature of both climate and workplace environments are related to increased urolithiasis risk. Public health intervention strategies need to be developed to prevent those operating in high-risk areas or occupations from being exposed to high ambient temperature.

\section{References}

1. Ziemba JB, Matlaga BR. Epidemiology and economics of nephrolithiasis. Investig Clin Urol 2017 Sep;58(5):299-306. https://doi.org/10.4111/icu.2017.58.5.299.

2. Menon M. Urinary lithiasis: etiology, diagnosis, and medical management. Campbell's urology 1998:Ch. 91.

3. Elliott JP Jr, Gordon JO, Evans JW, Platt L. A stone season. A 10 -year retrospective study of 768 surgical stone cases with respect to seasonal variation. J Urol 1975 Oct;114(4):574-7. https://doi.org/10.1016/S0022-5347(17)67085-X.

4. Levinson AA, Mandin H. Seasonal variations in the incidence of kidney stones in Calgary, Alberta, Canada. Clin Nephrol 1985 Jul;24(1):50-1.

5. al-Hadramy MS. Seasonal variations of urinary stone colic in Arabia. J Pak Med Assoc 1997 Nov;47(11):281-4.

6. Geraghty RM, Proietti S, Traxer O, Archer M, Somani BK. Worldwide impact of warmer seasons on the incidence of renal colic and kidney stone disease: evidence from a systematic review of literature. J Endourol 2017 Aug;31(8):729-35. https://doi.org/10.1089/end.2017.0123. 
7. Atan L, Andreoni C, Ortiz V, Silva EK, Pitta R, Atan F et al. High kidney stone risk in men working in steel industry at hot temperatures. Urology 2005 May;65(5):858-61. https:// doi.org/10.1016/j.urology.2004.11.048.

8. Borghi L, Meschi T, Amato F, Novarini A, Romanelli A, Cigala F. Hot occupation and nephrolithiasis. J Urol 1993 Dec;150(6):1757-60. https://doi.org/10.1016/S00225347(17)35887-1.

9. Luo H, Turner LR, Hurst C, Mai H, Zhang Y, Tong $\mathrm{S}$. Exposure to ambient heat and urolithiasis among outdoor workers in Guangzhou, China. Sci Total Environ 2014 Feb;472:1130-6. https://doi.org/10.1016/j. scitotenv.2013.11.042.

10. Higgins JP, Altman DG, Gøtzsche PC, Jüni P, Moher D, Oxman AD et al.; Cochrane Bias Methods Group; Cochrane Statistical Methods Group. The Cochrane Collaboration's tool for assessing risk of bias in randomised trials. BMJ 2011 Oct;343:d5928. https://doi.org/10.1136/bmj.d5928.

11. Borenstein M, Hedges LV, Higgins JP, Rothstein HR. Introduction to meta-analysis: John Wiley \& Sons 2009:41-3.

12. Higgins JP, Thompson SG. Quantifying heterogeneity in a meta-analysis. Stat Med 2002 Jun;21(11):1539-58. https:// doi.org/10.1002/sim.1186.

13. Chen H, Manning AK, Dupuis J. A method of moments estimator for random effect multivariate meta-analysis. Biometrics 2012 Dec;68(4):1278-84. PubMed https://doi. $\operatorname{org} / 10.1111 /$ j.1541-0420.2012.01761.x

14. Lee S, Kim MS, Kim JH, Kwon JK, Chi BH, Kim JW et al. Daily Mean Temperature Affects Urolithiasis Presentation in Seoul: a Time-series Analysis. J Korean Med Sci 2016 May;31(5):750-6. https://doi.org/10.3346/ jkms.2016.31.5.750.

15. Ordon M, Welk B, Li Q, Wang J, Lavigne E, Yagouti A et al. Ambient Temperature and the Risk of Renal Colic: A Population-Based Study of the Impact of Demographics and Comorbidity. J Endourol 2016 Oct;30(10):1138-43. https:// doi.org/10.1089/end.2016.0374.

16. Pin NT, Ling NY, Siang LH. Dehydration from outdoor work and urinary stones in a tropical environment. Occup Med (Lond) 1992 Feb;42(1):30-2. https://doi.org/10.1093/ occmed/42.1.30.

17. Safarinejad MR. Adult urolithiasis in a population-based study in Iran: prevalence, incidence, and associated risk factors. Urol Res 2007 Apr;35(2):73-82. https://doi. org/10.1007/s00240-007-0084-6.

18. Tasian GE, Pulido JE, Gasparrini A, Saigal CS, Horton BP, Landis JR et al.; Urologic Diseases in America Project. Daily mean temperature and clinical kidney stone presentation in five U.S. metropolitan areas: a time-series analysis. Environ Health Perspect 2014 Oct;122(10):1081-7. https://doi. org/10.1289/ehp.1307703.

19. Yang C, Chen X, Chen R, Cai J, Meng X, Wan Y et al. Daily ambient temperature and renal colic incidence in Guangzhou, China: a time-series analysis. Int J Biometeorol 2016 Aug;60(8):1135-42. https://doi.org/10.1007/s00484015-1106-7.
20. Buttigieg J, Attard S, Carachi A, Galea R, Fava S. Nephrolithiasis, stone composition, meteorology, and seasons in Malta: is there any connection? Urol Ann 2016 Jul-Sep;8(3):325-32. https://doi.org/10.4103/09747796.184892 .

21. Cepeda Delgado M, López Izquierdo R, Amón Sesmero JH, Del Pozo Vegas C, Álvarez Manzanares J. Epidemiological Characteristics of Renal Colic and Climate-Related Causes in a Continental Area in Spain. Urol Int 2015;95(3):309-13. https://doi.org/10.1159/000431102.

22. Chauhan V, Eskin B, Allegra JR, Cochrane DG. Effect of season, age, and gender on renal colic incidence. Am J Emerg Med 2004 Nov;22(7):560-3. https://doi. org/10.1016/j.ajem.2004.08.016.

23. Chen YK, Lin HC, Chen CS, Yeh SD. Seasonal variations in urinary calculi attacks and their association with climate: a population based study. J Urol 2008 Feb;179(2):564-9. https://doi.org/10.1016/j.juro.2007.09.067.

24. Gaziev G, Asimakopoulos AD, Wadhwa K, Topazio L, Germani S, Miano R. The influence of environmental conditions on the incidence of renal colic in Rome. Urologia 2016 May;83(2):77-82. https://doi.org/10.5301/ uro.5000170.

25. Lin KJ, Lin $\mathrm{PH}$, Chu $\mathrm{SH}$, Chen HW, Wang TM, Chiang YJ et al. The impact of climate factors on the prevalence of urolithiasis in Northern Taiwan. Biomed J 2014 Jan-Feb;37(1):24-30. https://doi.org/10.4103/23194170.117888 .

26. Sirohi M, Katz BF, Moreira DM, Dinlenc C. Monthly variations in urolithiasis presentations and their association with meteorologic factors in New York City. J Endourol 2014 May;28(5):599-604. https://doi.org/10.1089/end.2013.0680.

27. Freeg MA, Sreedharan J, Muttappallymyalil J, Venkatramana M, Shaafie IA, Mathew E et al. A retrospective study of the seasonal pattern of urolithiasis. Saudi J Kidney Dis Transpl 2012 Nov;23(6):1232-7.

28. Condemi V, Gestro M, Dozio E, Tartaglino B, Corsi Romanelli MM, Solimene U et al. Association with meteoclimatological factors and daily emergency visits for renal colic and urinary calculi in Cuneo, Italy. A retrospective observational study, 2007-2010. Int J Biometeorol 2015 Mar;59(3):249-63. https://doi.org/10.1007/s00484-0140861-1.

29. Lo SS, Johnston R, Al Sameraaii A, Metcalf PA, Rice ML, Masters JG. Seasonal variation in the acute presentation of urinary calculi over 8 years in Auckland, New Zealand. BJU Int $2010 \mathrm{Jul} ; 106(1): 96-101$. https://doi.org/10.1111/j.1464410X.2009.09012.x.

30. Park HK, Bae SR, Kim SE, Choi WS, Paick SH, Ho K et al. The effect of climate variability on urinary stone attacks: increased incidence associated with temperature over $18{ }^{\circ} \mathrm{C}$ : a population-based study. Urolithiasis 2015 Feb;43(1):89-94. https://doi.org/10.1007/s00240-014-07415.

31. Borg M, Bi P, Nitschke M, Williams S, McDonald S. The 
impact of daily temperature on renal disease incidence: an ecological study. Environ Health 2017 Oct;16(1):114. https://doi.org/10.1186/s12940-017-0331-4.

32. Fletcher BA, Lin S, Fitzgerald EF, Hwang SA. Association of summer temperatures with hospital admissions for renal diseases in New York State: a case-crossover study. Am J Epidemiol 2012 May;175(9):907-16. https://doi. org/10.1093/aje/kwr417.

33. Malig BJ, Wu XM, Guirguis K, Gershunov A, Basu R. Associations between ambient temperature and hepatobiliary and renal hospitalizations in California, 1999 to 2009. Environ Res 2019 Oct;177:108566. https://doi. org/10.1016/j.envres.2019.108566.

34. Pincus S, Macbean C, Taylor D. The effects of temperature, age and sex on presentations of renal colic in Melbourne, Australia. Eur J Emerg Med 2010 Dec;17(6):328-31. https:// doi.org/10.1097/MEJ.0b013e32833547b7.

35. Cervellin G, Comelli I, Comelli D, Cortellini P, Lippi G, Meschi $\mathrm{T}$ et al. Regional short-term climate variations influence on the number of visits for renal colic in a large urban Emergency Department: results of a 7-year survey. Intern Emerg Med 2011 Apr;6(2):141-7. https://doi. org/10.1007/s11739-011-0518-6.

36. Cervellin G, Comelli I, Comelli D, Meschi T, Lippi G, Borghi L. Mean temperature and humidity variations, along with patient age, predict the number of visits for renal colic in a large urban Emergency Department: results of a 9-year survey. J Epidemiol Glob Health 2012 Mar;2(1):31-8. https://doi.org/10.1016/j.jegh.2012.01.001.

37. Boscolo-Berto R, Dal Moro F, Abate A, Arandjelovic G, Tosato F, Bassi P. Do weather conditions influence the onset of renal colic? A novel approach to analysis. Urol Int 2008;80(1):19-25. https://doi.org/10.1159/000111724.
38. Arias Vega R, Pérula de Torres LA, Jiménez García C, Carrasco Valiente J, Requena Tapia MJ, Cano Castiñeira R et al. Comorbilidad y factores sociodemográficos asociados a litiasis renal en personas de 40 a 65 años: estudio transversal [Comorbidity and socio-demographic factors associated with renal lithiasis in persons aged 40 to 65 : A crosssectional study]. Med Clin (Barc) 2017 Nov;149(9):383-90. https://doi.org/10.1016/j.medcli.2017.03.037.

39. Brikowski TH, Lotan Y, Pearle MS. Climate-related increase in the prevalence of urolithiasis in the United States. Proc Natl Acad Sci USA 2008 Jul;105(28):9841-6. https://doi.org/10.1073/pnas.0709652105.

40. Power C, Barker DJ, Blacklock NJ. Incidence of renal stones in 18 British towns. A collaborative study. Br J Urol 1987 Feb;59(2):105-10. https://doi.org/10.1111/j.1464410X.1987.tb04798.x.

41. Fakheri RJ, Goldfarb DS. Ambient temperature as a contributor to kidney stone formation: implications of global warming. Kidney Int 2011 Jun;79(11):1178-85. https://doi. org/10.1038/ki.2011.76.

42. Lotan Y, Daudon M, Bruyère F, Talaska G, Strippoli G, Johnson RJ et al. Impact of fluid intake in the prevention of urinary system diseases: a brief review. Curr Opin Nephrol Hypertens 2013 May;22 Suppl 1:S1-10. https://doi. org/10.1097/MNH.0b013e328360a268.

43. Eisner BH, Sheth S, Herrick B, Pais VM Jr, Sawyer M, Miller $\mathrm{N}$ et al. The effects of ambient temperature, humidity and season of year on urine composition in patients with nephrolithiasis. BJU Int 2012 Dec;110 11 Pt C:E1014-7. https://doi.org/10.1111/j.1464-410X.2012.11186.x.

Received for publication: 27 June 2019 